Journal of Applied Finance \& Banking, Vol. 10, No. 6, 2020, 153-174

ISSN: 1792-6580 (print version), 1792-6599(online)

https://doi.org/10.47260/jafb/1068

Scientific Press International Limited

\title{
Shadow Prices of Non-performing Loans for Chinese Banks in the Post-Crisis Era
}

\author{
Shirong Zhao
}

\begin{abstract}
This paper examines how non-performing loans (NPLs) affect Chinese commercial banks before, during, and after the 2008 global financial crisis as well as the subsequent 2008--2010 stimulus. By accounting for NPLs as undesirable outputs, banks' technical efficiency is estimated using directional output distance function. The envelop theorem is applied to calculate the shadow price of NPLs. The shadow price of NPLs is the opportunity cost of reducing NPLs by one Chinese yuan. Empirical results show that the four major state-owned banks are the least technically efficient while foreign banks are the most efficient over the sample period 2007-2014. I also find that the crisis has a negative effect on banks' technical efficiency while the stimulus initially has a positive effect on four major stateowned commercial banks and joint-stock commercial banks, but later shows a negative effect with a higher default ratio and lower efficiency. Finally, the data show that the stimulus has greatly increased the shadow price of NPLs for four major state-owned commercial banks. Starting in 2011, the shadow prices of NPLs for four major state-owned commercial banks are much higher than all other bank types.
\end{abstract}

JEL classification numbers: G21, L11, C13

Keywords: the directional output distance function, shadow price of nonperforming loans, technical efficiency, Chinese banks.

\footnotetext{
${ }^{1}$ Postdoctoral Fellow at Department of Clinical Pharmacy and Translational Science, University of Tennessee Health Science Center; and graduate student at School of Mathematical and Statistical Science, Clemson University.
}

Article Info: Received: July 31, 2020. Revised: September 15, 2020.

Published online: September 21, 2020. 


\section{Introduction}

The recent global financial crisis (GFC) started from the subprime crisis of the housing mortgage market in the U.S. in 2007 and caused many banks unexpected losses and even failures. Bank failures then led to a credit shortage, plunging the global economy into a deep recession. For these reasons, more focus has been drawn on the soundness and stability of the banking sector.

The period 2007-2014 was especially disruptive to the Chinese banking sector. In 2008, the GFC had a substantial adverse effect on China's exports. To mitigate the impact of the GFC on China's economy, China's central government announced a plan in November 2008 to stimulate domestic demand. The stimulus plan invested 4 trillion Chinese yuan or Renminbi (RMB) in rural infrastructure, transportation, and other areas by the end of 2010. State-owned enterprises (SOEs) mainly undertook investment plans. China's banks have played an essential role in the stimulus since they are the primary funding sources for domestic investments. To support banks making loans to SOEs and other smaller enterprises, China's central bank, People's Bank of China (PBC), lowered the reserve ratio requirement, the borrowing, and lending benchmark rate, and even canceled the credit limit on commercial banks. For example, the central bank lowered requirement reserve ratio from 17 percent on October 8th, 2008, to 15.5 percent on January 18th, 2010. With the stimulus's help, China's GDP growth averaged 10 percent while the GDP of North America and Europe was contracting.

However, many problems accompanied the stimulus. One main concern is the quick rise of non-performing loans (NPLs) after the stimulus since many Chinese banks took the government's implicit order to make loans without fully evaluating the credit risk of these loans. Thus the stimulus initially increased the total loans for Chinese banks and decreased the default ratio. However, some years later, after the stimulus, many loans made during the stimulus defaulted and caused an increase in the default ratio. Since NPLs are critical in impacting the development and health of the banking sector, some studies have taken NPLs into account when studying the performance of the banking sector (Guarda et al. (2013), Zhu et al. (2015), and Partovi and Matousek (2019)). Among these papers, NPLs are typically considered by-products of the banks' production process and only occur after banks have lent out the loans. Therefore, NPLs are usually modeled as undesirable or bad outputs, while net or good loans and securities are thought of as desirable or good outputs. In the recent crisis context, some studies have found that the increase in NPLs during the GFC leads to lower efficiency levels for banks (Sufian and Shah Habibullah (2010), Vu and Turnell (2011), Matousek et al. (2015), Tarchouna et al. (2019), and Hasannasab et al. (2019)).

More importantly, to understand the potential effect of the crisis and stimulus, policymakers and bank managers need to know the cost of incurring NPLs. However, since there is no observable market price for NPLs, it must be estimated from the empirical data. Few banking studies use the shadow price model initially developed by Färe et al. (1993) to calculate the price of NPLs. In the studies, the 
unobservable (shadow) price of NPLs can be estimated from the observable market price of desirable outputs and the physical tradeoff between the good and bad outputs. The shadow price of NPLs is measured as the loss of the banks' revenue due to the loss of good outputs when banks are lessening one unit of NPL. Thus the shadow price of NPLs is the opportunity cost of diminishing one unit of NPLs. The shadow price model can be used to estimate the price of NPLs.

Fukuyama and Weber (2008a) may be the first to estimate the shadow price of NPLs for the banking sector. They use the deterministic linear programming method of Aigner and Chu (1968) to evaluate the shadow prices of Japanese banks for the period 2001-2004, and they find that Regional banks have a higher cost of reducing NPLs than Shinkin banks. Fukuyama and Weber (2008b) employ both parametric and nonparametric form of the directional output distance function in the Japanese banking sector from 2002 to 2004. Fukuyama and Weber find that the shadow price estimates for the two methods diverge. George Assaf et al. (2013) employ a Bayesian stochastic frontier approach and account for NPLs to analyze the efficiency and productivity of Turkish banks from 2002 to 2010. They find that Foreign banks show lower values of shadow price than domestic banks, and the shadow prices of NPLs have increased in both 2009 and 2010, due to the impact of the GFC. Tarchouna et al. (2019) use the directional output distance function for U.S. commercial banks over 2000-2013. They find that the shadow prices of NPLs of small and medium-sized banks are lower than those of large banks, and the shadow prices of NPLs have increased significantly for large banks during the GFC. Hasannasab et al. (2019) employ directional distance function for U.S. banks over the period 2002-2016. They find that the actual price of good loans is much lower than the estimated shadow price of NPLs during 2003-2007, after which these two prices converge to each other.

To the best of my knowledge, there are no studies evaluating the shadow price of NPLs in the Chinese banking sector. Given the importance of banks in the Chinese economy, it is reasonable to investigate the technical efficiency and shadow price of NPLs for China's banks before, during, and after the 2008 global financial crisis and the subsequent 2008-2010 China's stimulus. Therefore, this paper both (i) contributes to the banking literature by shedding light on the effects of the recent crisis and the stimulus on Chinese commercial banks, and (ii) is the first study that estimates the shadow price of NPLs in the Chinese banking sector. The remainder of the paper is organized as follows. Section 2 provides background on the Chinese banking industry. Section 3 introduces the estimation model based on the directional output distance function. Section 4 describes the data, variable specification and summary statistics. Empirical results are shown in Section 5. Conclusion and policy suggestions are discussed in Section 6.

\section{Background on the Chinese Banking Industry}

Currently, Chinese commercial banks consist of the four major state-owned commercial banks (SOCBs), the joint-stock commercial banks (JSCBs), city 
commercial banks (CCBs), rural commercial banks (RCB), and foreign banks (FBs). Before 1978, the only bank in China was PBC. The PBC took on the responsibilities of central and commercial banking. After the reforms in 1978, the banking system was expanded by establishing four SOCBs: Industrial and Commercial Bank of China, China Construction Bank, Agricultural Bank of China, and Bank of China. These four banks took over the role of commercial banking from the PBC and the PBC transitioned to the role of only implementing monetary policy. Due to 1994's financial reforms, China's banking system has became diversified as SOCBs were encouraged to operate independently from the government and more banks were established. In 2003, aiming to improve the efficiency and competitiveness of the domestic banks, China's government started a new reform on the ownership of domestic banks (especially the SOCBs) and hope that they could all be listed in the market. In 2010, the Agricultural Bank of China became the last bank listed on the market among the SOCBs. Although they have filed IPOs, they are still under government control to some extent since the government still holds the largest shares of SOCBs. On the other hand, they have become more market-oriented than before.

Starting in 1986, 13 JSCBs were created. They are owned by local governments, SOEs, and private sector. They mainly provide service for small and medium-sized enterprises. Having absorbed management experience from foreign banks, these JSCBs are more competitive and market-oriented than SOCBs, even though they are quite younger and smaller compared to SOCBs.

Since the mid-1990s, Chinese governments have created CCBs by restructuring and consolidating urban credit cooperatives. The capital for CCBs comes from local governments and urban enterprises. They mainly lend to SMEs, collectives, and local residents. Although there are many CCBs, their size is quite small because of regulations from the government. For instance, some CCBs can only operate in a certain area.

In addition, RCBs are also one important part of the Chinese banking sector. They mainly provide service for the agricultural sector and other rural areas. Historically bank lending to rural areas is not sufficient. To encourage more lending to rural areas, the China Banking Regulation Commission has considered and initialized some new policies, such as tax cuts, a lower reserve requirement for rural banks than other banks.

Since 2006, all of the FBs were permitted to conduct RMB business and were treated the same as the domestic banks. In 2014, in order to enact even more reforms on banks, reduce financial risk, and provide better banking services, three private banks solely owned by private companies were allowed to open by the China Banking Regulation Commission. As of September 2018, there are already 17 private banks, which have greatly enriched China's banking sector. 


\section{Model}

By incorporating undesirable byproducts into a production frontier, Färe et al. (1993) first derive the shadow price of undesirable outputs by exploiting the duality between the revenue function and the output distance function. The shadow price is explained as the opportunity cost in terms of foregone revenue. The ratio of any two of these output shadow prices is equivalent to their marginal rate of transformation (MRT). A rapidly emerging shadow price literature mainly follows this approach with different choice of distance functions and frontier estimation methods. Zhou et al. (2014) conducts a systematic review of the studies on estimating shadow prices of undesirable outputs with efficiency models. Färe et al. (2005) uses a quadratic directional output distance function to estimate the shadow price of SO2 for 209 U.S. electric utilities from 1993 to 1997. Zhao (2020) uses a convex quantile regression method to simultaneously estimate shadow prices for three pollutants. Currently the directional distance function has been the most popular because it could be used to estimate multi-input and multi-output frontier (e.g. Boyd et al. (2002), Färe et al. (2005), Lee and Zhou (2015)). Both nonparametric and parametric techniques are employed to estimate the frontier. A nonparametric method, like Data Envelopment Analysis (DEA) without specifying any functional form, applies linear programming method to generate a piece-wise linear form of the production frontier. However, the DEA method cannot always produce unique shadow price estimates. Alternatively, a parametric method like quadratic or translog specification is commonly used since it yields a smooth frontier. The Aigner and Chu (1968) method can be used to estimate the parameters by minimizing the sum of deviations of the distance function values from the production frontier subject to several underlying production technology constraints. The constraints include feasibility, monotonicity, and translation properties of the distance function. This method has been widely used to compute the distance function and then recover shadow prices of NPLs by Fukuyama and Weber (2008a), Fukuyama and Weber (2008b), and Hasannasab et al. (2019). In this study, to estimate the shadow price of NPLs for Chinese banks, I also employ the Aigner and Chu (1968) method by specifying a quadratic functional form for the directional output distance function.

To establish notation, assume that there are $\mathrm{n}=(1,2, \ldots, N)$ banks. Each bank uses $\mathrm{x}=\left(x_{1}, x_{2}, \ldots, x_{p}\right) \in R_{+}^{P}$ inputs to jointly produce desirable outputs $\mathrm{y}=$ $\left(\mathrm{y}_{1}, \mathrm{y}_{2}, \ldots, \mathrm{y}_{\mathrm{q}}\right) \in \mathrm{R}_{+}^{\mathrm{Q}}$ and undesirable outputs $\mathrm{b}=\left(b_{1}, b_{2}, \ldots, b_{l}\right) \in R_{+}^{L}$. In addition, I assume that both input and output direction vectors $g^{x}=\left(g_{1}^{x}, g_{2}^{x}, \ldots, g_{p}^{x}\right) \in$ $R_{+}^{P}, g^{y}=\left(g_{1}^{y}, g_{2}^{y}, \ldots, g_{q}^{y}\right) \in R_{+}^{Q}, g^{b}=\left(g_{1}^{b}, g_{2}^{b}, \ldots, g_{l}^{b}\right) \in R_{+}^{L}$ have been chosen. The production set of banks can be displayed as follows:

$$
\Psi:=\{(x, y, b) \mid x \text { can produce }(y, b)\}
$$


The directional distance function is defined as:

$$
\mathrm{D}\left(x, y, b ; g^{x}, g^{y}, g^{b}\right)=\max \left\{\omega:\left(x-\omega g^{x}, y+\omega g^{y}, b-\omega g^{b}\right) \in \Psi\right\} .
$$

The distance function needs to satisfy the representation property

$$
\Psi=\left\{(x, y, b) \mid \mathrm{D}\left(x, y, b ; g^{x}, g^{y}, g^{b}\right) \geq 0\right\} .
$$

Equation (2) shows that, following the direction $g=\left(g^{x}, g^{y}, g^{b}\right)$, the bank can achieve the maximum value of $\mathrm{D}\left(\mathrm{x}, \mathrm{y}, \mathrm{b} ; \mathrm{g}^{\mathrm{x}}, \mathrm{g}^{\mathrm{y}}, \mathrm{g}^{\mathrm{b}}\right)$ for the increase in desirable outputs and simultaneous decrease in inputs and bad outputs. If $\mathrm{D}\left(\mathrm{x}, \mathrm{y}, \mathrm{b} ; \mathrm{g}^{\mathrm{x}}, \mathrm{g}^{\mathrm{y}}, \mathrm{g}^{\mathrm{b}}\right)=0$, then the bank lies on the frontier and is the most technically efficient. However, if $\mathrm{D}\left(x, y, b ; g^{x}, g^{y}, g^{b}\right)>0$ then the bank lies under the frontier and inside of the production set $\Psi$, and it will be considered as technically inefficient. The larger value of $\mathrm{D}\left(x, y, b ; g^{x}, g^{y}, g^{b}\right)$ the more inefficient the bank. The distance function also needs to satisfy translation property

$$
\begin{gathered}
\mathrm{D}\left(x-\alpha g^{x}, y+\alpha g^{y}, b-\alpha g^{b} ; g^{x}, g^{y}, g^{b}\right)=\mathrm{D}\left(x, y, b ; g^{x}, g^{y}, g^{b}\right)-\alpha, \\
\alpha \in R .
\end{gathered}
$$

To estimate the shadow prices, I first need to parameterize the distance function $\mathrm{D}\left(x, y, b ; g^{x}, g^{y}, g^{b}\right)$. Following Fukuyama and Weber (2008a), Fukuyama and Weber (2008b), and Hasannasab et al. (2019), I employ a quadratic functional form:

$$
\begin{aligned}
\mathrm{D}\left(\mathrm{x}, \mathrm{y}, \mathrm{b} ; \mathrm{g}^{\mathrm{x}}, \mathrm{g}^{\mathrm{y}}, \mathrm{g}^{\mathrm{b}}\right) & \\
= & \alpha_{0}+\sum_{p=1}^{P} \alpha_{p} x_{p}+\sum_{q=1}^{Q} \beta_{q} y_{q}+\sum_{l=1}^{L} \gamma_{l} b_{l}+\frac{1}{2} \sum_{p=1}^{P} \sum_{p^{\prime}=1}^{P} \alpha_{p p^{\prime}}-x_{p} x_{p}, \\
& +\frac{1}{2} \sum_{q=1}^{Q} \sum_{q^{\prime}=1}^{Q} \beta_{q q^{\prime}}-y_{q} y_{q^{\prime}}+\frac{1}{2} \sum_{l=1}^{L} \sum_{l^{\prime}=1}^{L} \gamma_{l l^{\prime}} b_{l^{\prime}} b_{l^{\prime}} \\
& +\sum_{p=1}^{P} \sum_{q=1}^{Q^{Q}} \delta_{p q} x_{p} y_{q}+\sum_{p=1}^{P} \sum_{l=1}^{L} v_{p l} x_{p} b_{l}+\sum_{q=1}^{Q} \sum_{l=1}^{L} \mu_{q l} y_{q} b_{l}
\end{aligned}
$$


The distance functions need to satisfy several underlying technology constraints, including feasibility, monotonicity, and translation properties. Following Aigner and Chu (1968), the quadratic distance function can be estimated by solving the following linear programming problem

s.t.

$$
\min \sum_{n=1}^{N} D\left(x^{n}, y^{n}, b^{n} ; g^{x}, g^{y}, g^{b}\right)
$$

$$
\begin{aligned}
& \mathrm{D}\left(\mathrm{x}^{\mathrm{n}}, \mathrm{y}^{\mathrm{n}}, \mathrm{b}^{\mathrm{n}} ; \mathrm{g}^{\mathrm{x}}, \mathrm{g}^{\mathrm{y}}, \mathrm{g}^{\mathrm{b}}\right) \geq 0, \forall \mathrm{n}, \quad \text { (feasibility) } \\
& \partial \mathrm{D}\left(\mathrm{x}^{\mathrm{n}}, \mathrm{y}^{\mathrm{n}}, \mathrm{b}^{\mathrm{n}} ; \mathrm{g}^{\mathrm{x}}, \mathrm{g}^{\mathrm{y}}, \mathrm{g}^{\mathrm{b}}\right) / \partial \mathrm{x}_{\mathrm{p}} \geq 0, \forall \mathrm{p}, \quad \text { (monotonicity) } \\
& \partial D\left(x^{n}, y^{n}, b^{n} ; g^{x}, g^{y}, g^{b}\right) / \partial b_{l} \geq 0, \forall l, \quad \text { (monotonicity) } \\
& \partial D\left(x^{n}, y^{n}, b^{n} ; g^{x}, g^{y}, g^{b}\right) / \partial y_{q} \leq 0, \forall q, \quad \text { (monotonicity) } \\
& -\sum_{p=1}^{P} \alpha_{p} g_{p}^{x}+\sum_{q=1}^{Q} \beta_{q} g_{q}^{y}-\sum_{l=1}^{L} \gamma_{l} g_{l}^{b}=-1, \quad \text { (translation) } \\
& -\sum_{p=1}^{P} \delta_{p q} g_{p}^{x}+\sum_{q^{\prime}=1}^{Q} \beta_{q q^{\prime}} g_{q}^{y}-\sum_{l=1}^{L} \mu_{q l} g_{l}^{b}=0, \forall m, \quad \text { (translation) } \\
& -\sum_{p=1}^{P} v_{p l} g_{p}^{x}+\sum_{q=1}^{Q} \mu_{q l} g_{q}^{y}-\sum_{l^{\prime}=1}^{L} \gamma_{l l^{\prime}} g_{l}^{b}=0, \forall l, \quad \text { (translation) } \\
& -\sum_{p^{\prime}=1}^{P} \alpha_{p p^{\prime}} g_{p}^{x}+\sum_{q=1}^{Q} \delta_{p q} g_{q}^{y}-\sum_{l=1}^{L} v_{p l} g_{l}^{b}=0, \forall p, \quad \text { (translation) } \\
& \alpha_{p p^{\prime}}=\alpha_{p^{\prime} p}, \forall p \neq p^{\prime} ; \beta_{q q^{\prime}}=\beta_{q^{\prime} q}, \forall q \neq q^{\prime} ; \gamma_{l l^{\prime}}=\gamma_{l^{\prime} l}, \forall l \\
& \neq l^{\prime} \text {. }
\end{aligned}
$$


Moreover, the partial derivatives of the distance function can be calculated as

$$
\begin{gathered}
\partial D\left(x^{n}, y^{n}, b^{n} ; g^{x}, g^{y}, g^{b}\right) / \partial x_{p} \\
=\alpha_{p}+\sum_{p^{\prime}}^{P} \alpha_{p p^{\prime}} x_{p^{\prime}}^{n}+\sum_{q=1}^{Q} \delta_{p q} y_{q}^{n}+\sum_{l=1}^{L} v_{p l} b_{l}^{n}, \forall n \\
\partial D\left(x^{n}, y^{n}, b^{n} ; g^{x}, g^{y}, g^{b}\right) / \partial b_{l} \\
=\beta_{q}+\sum_{q^{\prime}}^{Q} \beta_{q q^{\prime}} y_{q^{\prime}}^{n}+\sum_{p=1}^{P} \delta_{p q} x_{p}^{n}+\sum_{l=1}^{L} \mu_{q l} b_{l}^{n}, \forall n \\
\partial D\left(x^{n}, y^{n}, b^{n} ; g^{x}, g^{y}, g^{b}\right) / \partial y_{q}=\gamma_{l}+\sum_{l^{\prime}=1}^{L} \gamma_{l l^{\prime}} b_{l^{\prime}}^{n}+\sum_{p=1}^{P} v_{p l} x_{p}^{n}+\sum_{q=1}^{Q} \mu_{q l} y_{q}^{n}, \forall n .
\end{gathered}
$$

To estimate shadow price of NPLs, following Färe et al. (2005), banks are modelled to maximize the revenue subject to the directional output distance function:

$$
R\left(x, p_{y}, p_{b}\right)=\max _{y, b}\left\{p_{y} y-p_{b} b \mid D\left(x^{n}, y^{n}, b^{n} ; g^{x}, g^{y}, g^{b}\right) \geq 0\right\},
$$

where $\mathrm{p}_{\mathrm{y}}, \mathrm{p}_{\mathrm{b}}$ represent the price vectors of good outputs and bad outputs, and $\mathrm{g}^{\mathrm{x}}$ is set equal to 0 in distance function $D\left(x, y, b ; g^{x}, g^{y}, g^{b}\right)$ in order to get the directional output distance function. Applying the method of Lagrangian multipliers yields

$$
\max _{y, b, x} p_{y} y-p_{b} b-\lambda\left(D\left(x^{n}, y^{n}, b^{n} ; g^{x}=0, g^{y}, g^{b}\right)\right)
$$

The first-order conditions are

$$
\begin{aligned}
p_{y_{q}} & =\lambda \frac{\partial D\left(x^{n}, y^{n}, b^{n} ; g^{x}=0, g^{y}, g^{b}\right)}{\partial y_{q}} \\
-P_{b_{l}} & =\lambda \frac{\partial D\left(x^{n}, y^{n}, b^{n} ; g^{x}=0, g^{y}, g^{b}\right)}{\partial b_{l}} .
\end{aligned}
$$


Therefore, the shadow prices of bad outputs could be derived as follows:

$$
P_{b_{l}}=-P_{y_{q}} \frac{\frac{\partial D\left(x^{n}, y^{n}, b^{n} ; g^{x}=0, g^{y}, g^{b}\right)}{\partial b_{l}}}{\frac{\partial D\left(x^{n}, y^{n}, b^{n} ; g^{x}=0, g^{y}, g^{b}\right)}{\partial y_{q}}}, \forall q, l .
$$

All Chinese commercial banks are assumed to operate in the same production set $\Psi$ defined by Equation (1), and therefore they face the same frontier in the input-output space. Banks may have different business plans and hence may operate in different areas of the production set $\Psi$. The quadratic functional form is very flexible to capture the difference among banks because it gives a second-order approximation to the true production frontier. If one good output price is known and believed to be market price, the shadow price of non-performing loans could be computed using Equation (11).

\section{Data and Variable Specification}

The sample is an unbalanced panel including data from the balance sheets and income statements of commercial banks in China from 2007 to 2014. I have one year of data (2007) before the crisis, three years of data (2008-2010) during the crisis and the stimulus, and four years of data (2011-2014) after the stimulus. The primary data source is the BankScope database maintained by Bureau Van Dijk. According to the China Banking Regulation Committee, in 2014, China has 4 SOCBs, 12 JSCBs, 133 CCBs, 665 RCBs, and 41 FBs. The total assets in 2014 were 150.95 trillion RMB. In 2014, the sample includes four major state-owned commercial banks, 12 joint stock commercial banks, 58 city commercial banks, 17 rural commercial banks, and 22 foreign banks. The total assets of the sample are 108.90 trillion RMB, accounting for about 70 percent of China's commercial banks' total assets. Therefore, the sample is a good representation of all the commercial banks in China.

Following the intermediation approach in Sealey and Lindley (1977), P = 3 inputs, $\mathrm{Q}=2$ desirable outputs, and $\mathrm{L}=1$ undesirable output are defined for banks' production technology. Specifically, the two desirable output variables are defined as: net (good) loans $\left(y_{1}\right)$ and total securities $\left(y_{2}\right)$. The one undesirable output is the non-performing loan $(b)$ measured by loan impairment charges. The three input variables are defined as: total funding $\left(x_{1}\right)$, consisting of total customer deposits, deposits from banks, repos and cash collateral, other deposits and short-term borrowings, senior debt maturing after one year, subordinated borrowing, other funding, total long-term funding, derivatives, and trading liabilities; labor services, measured by personnel expenses $\left(x_{2}\right)$ ); and fixed assets $\left(x_{3}\right)$. The first input quantity $x_{1}$ captures non-equity sources of investment funds for the bank. The input-output specification is typical and standard, reflecting the basic production process of banks. According to Equation (11), to estimate the shadow price of NPLs, the 
observable market price of one good output needs to be chosen. I use, like Hasannasab et al. (2019), the market price of good loans. The price of good loans $\left(p_{1}\right)$ is defined as interest income on loans divided by net loans. All RMB amounts are measured in constant $2010 \mathrm{RMB}$.

Table 1: Summary Statistics for 2007-2014

\begin{tabular}{|c|c|c|c|c|c|c|}
\hline Mean/SD ${ }^{1}$ & All & $\mathrm{BF}$ & JSCB & $\mathrm{CCB}$ & $\mathrm{RCB}$ & $\mathrm{FB}$ \\
\hline \multicolumn{7}{|c|}{ Total Funding $\left(x_{1}\right)$} \\
\hline Mean & 974.326 & 10574.7 & 1726.57 & 142.099 & 139.727 & 59.307 \\
\hline SD & 2566.28 & 2437.96 & 1169.35 & 180.387 & 134.991 & 58.469 \\
\hline \multicolumn{7}{|c|}{ Labor Services $\left(x_{2}\right)$} \\
\hline Mean & 5.922 & 67.911 & 9.344 & 0.677 & 1.016 & 0.529 \\
\hline SD & 16.318 & 15.218 & 6.238 & 0.674 & 1.038 & 0.588 \\
\hline \multicolumn{7}{|c|}{ Fixed Asset $\left(x_{3}\right)$} \\
\hline Mean & 9.11 & 114.407 & 11.312 & 1.047 & 1.496 & 0.302 \\
\hline $\mathrm{SD}$ & 27.421 & 24.149 & 11.369 & 1.137 & 1.394 & 0.663 \\
\hline \multicolumn{7}{|c|}{ Net Loans $\left(y_{1}\right)$} \\
\hline Mean & 523.641 & 5784.37 & 934.975 & 63.12 & 69.076 & 31.862 \\
\hline $\mathrm{SD}$ & 1420.41 & 1547.41 & 672.933 & 84.47 & 60.784 & 30.221 \\
\hline \multicolumn{7}{|c|}{ Securities $\left(y_{2}\right)$} \\
\hline Mean & 244.596 & 2811.09 & 350.744 & 44.629 & 37.448 & 10.483 \\
\hline $\mathrm{SD}$ & 675.104 & 639.304 & 273.596 & 53.809 & 40.956 & 15.939 \\
\hline \multicolumn{7}{|c|}{ Non-performing Loans $(b)$} \\
\hline Mean & 3.175 & 33.436 & 6.003 & 0.482 & 0.463 & 0.151 \\
\hline $\mathrm{SD}$ & 8.655 & 12.915 & 5.413 & 0.658 & 0.421 & 0.25 \\
\hline \multicolumn{7}{|l|}{ Asset } \\
\hline Mean & 1065.94 & 11596.2 & 1876.17 & 155.132 & 154.1 & 66.831 \\
\hline SD & 2815.36 & 2709.63 & 1283.59 & 194.964 & 147.43 & 64.614 \\
\hline \multicolumn{7}{|c|}{ Loan Price $\left(p_{1}\right)$} \\
\hline Mean & 0.064 & 0.056 & 0.062 & 0.071 & 0.069 & 0.049 \\
\hline $\mathrm{SD}$ & 0.016 & 0.007 & 0.01 & 0.016 & 0.011 & 0.012 \\
\hline
\end{tabular}

${ }^{1}$ Except for price variables, the units for all the variables is Billions of 2010 RMB.

Table 1 shows the summary statistics for inputs, outputs, and prices for 2007-2014. In decreasing order of the size of total assets lies the SOCBs, JSCBs, CCBs, RCBs, and FBs. Table 2 lists the number of banks by each year and each bank type. 
Table 2: Number of Banks in the Sample over 2007-2014

\begin{tabular}{rrrrrr}
\hline Year & SOCBs & JSCBs & CCBs & RCBs & FBs \\
\hline 2007 & 3 & 6 & 7 & 1 & 3 \\
2008 & 4 & 8 & 12 & 2 & 11 \\
2009 & 4 & 9 & 12 & 2 & 7 \\
2010 & 4 & 11 & 22 & 6 & 14 \\
2011 & 4 & 11 & 34 & 9 & 11 \\
2012 & 4 & 13 & 47 & 11 & 19 \\
2013 & 4 & 12 & 59 & 16 & 19 \\
2014 & 4 & 12 & 58 & 17 & 22 \\
\hline
\end{tabular}

Figure 1 shows the trend charts of the loan default ratio $\left(b /\left(b+y_{1}\right)\right)$ by bank type. From 2007 to 2008, the default ratio increases for all types of banks except CCBs. This increase reflects that the global financial crisis brings a negative effect on the Chinese banking sector. However, from 2008 to 2010, the default ratio, in general, shows a decreasing trend for all bank types. The decrease in default ratio could be due to the expansion of the loans from the stimulus plan. After 2010, the default ratio increases again. The increase is the negative impact of the stimulus because from 2008 to 2010, many banks are forced to lend money without fully evaluating the credit risk. 


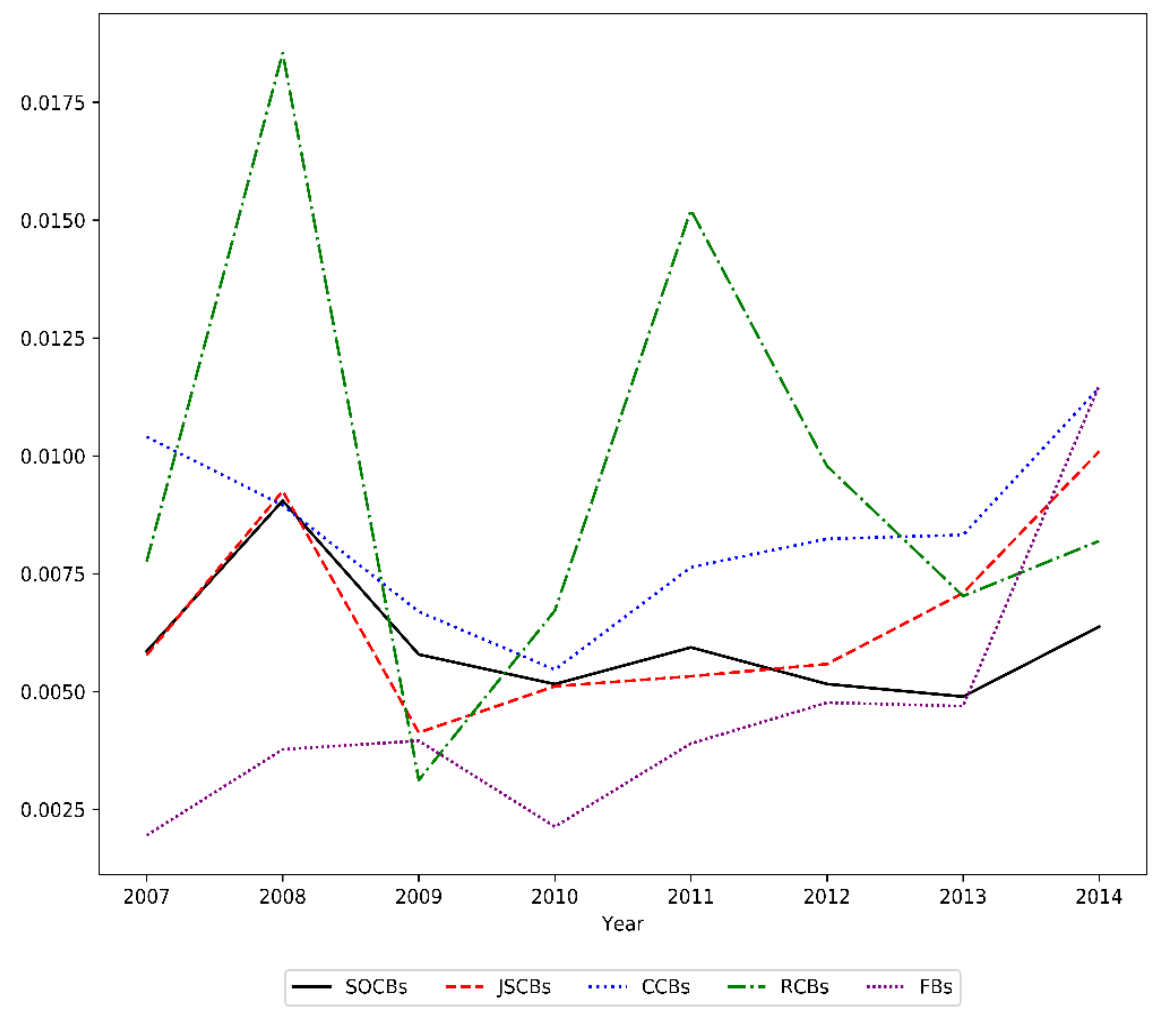

Figure 1: Default Ratio by Bank Type

Note: For each year and each bank type, the default ratio is weighted by the total loans $\left(b+y_{1}\right)$

Figure 2 shows the evolution of the market prices of good loans $\left(p_{1}\right)$ for each bank type over the sample period. The price of good loans, in general, increased from 2007 to 2008, then decreased from 2008 to 2010, after which it increased to 2012, and then decreased to 2014. The sharp increase in $p_{1}$ for all types of banks except CCBs could be explained by the GFC's negative effect. The sudden rise of the banking sector's uncertainty increases the risk and raises the price of the loans. The sharp decrease of $p_{1}$ for most bank types from 2008 to 2010 could be explained by the expansion effect of the stimulus plan, during which the central bank of China decreased both the loan interest rate and the reserve requirement ratio. 


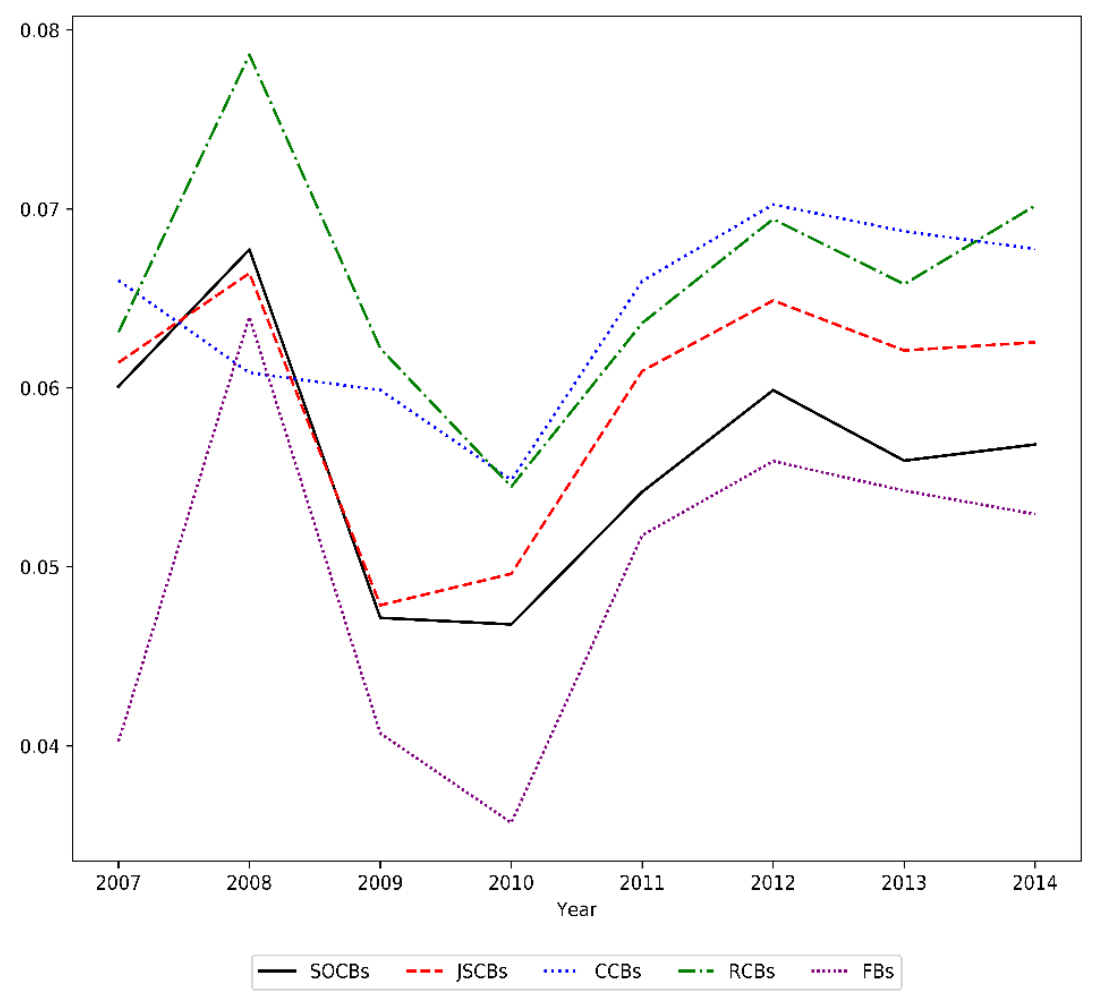

Figure 2: Place of Good (Net) Loans $\left(p_{1}\right)$

Note: For each year and each bank type, $p_{1}$ is weighted by good loans $\left(y_{1}\right)$

\section{Empirical Results}

The directional output distance function is estimated by setting the directional vector's values equal to the averages of corresponding output data. More specifically, I set $g^{y}=\bar{y}=(524,245), g^{b}=\bar{b}=3$. Table 3 reports the mean and standard deviation of technical efficiency scores by each year and each bank type. The technical efficiency score is defined as $1 /\left(1+D\left(x, y, b ; g^{x}=0, g^{y}, g^{b}\right)\right)$ so that the value of technical efficiency score is in the range of zero to one. A bank that produces on the frontier is technically efficient, and its technical efficiency score is equal to one. The larger the technical efficiency score, the more efficient the bank. Moreover, I report the average values of efficiency scores for each bank type over the sample period at the bottom of the table. Table 3 shows that the estimated efficiency of Chinese commercial banks has an mean value of 93.8 percent. This value suggests that holding the inputs fixed, Chinese commercial banks can raise good loans and total securities and simultaneously diminish the amounts of NPLs by about 6 percent. 
Table 3: Technical Efficiency Scores by Year and by Bank Type

\begin{tabular}{|c|c|c|c|c|c|c|}
\hline Mean/SD & All & SOCBs & JSCBs & $\mathrm{CCBs}$ & $\mathrm{RCBs}$ & FBs \\
\hline \multicolumn{7}{|l|}{2007} \\
\hline Mean & 0.939 & 0.792 & 0.947 & 0.974 & 0.978 & 0.973 \\
\hline $\mathrm{SD}$ & 0.081 & 0.116 & 0.04 & 0.013 & 0 & 0.017 \\
\hline \multicolumn{7}{|l|}{2008} \\
\hline Mean & 0.934 & 0.662 & 0.927 & 0.979 & 0.974 & 0.98 \\
\hline $\mathrm{SD}$ & 0.107 & 0.104 & 0.059 & 0.004 & 0.008 & 0.009 \\
\hline \multicolumn{7}{|l|}{2009} \\
\hline Mean & 0.949 & 0.734 & 0.969 & 0.981 & 0.979 & 0.982 \\
\hline SD & 0.1 & 0.174 & 0.036 & 0.002 & 0.005 & 0.008 \\
\hline \multicolumn{7}{|l|}{2010} \\
\hline Mean & 0.952 & 0.801 & 0.916 & 0.972 & 0.978 & 0.981 \\
\hline $\mathrm{SD}$ & 0.076 & 0.17 & 0.086 & 0.017 & 0.004 & 0.004 \\
\hline \multicolumn{7}{|l|}{2011} \\
\hline Mean & 0.931 & 0.684 & 0.845 & 0.963 & 0.974 & 0.974 \\
\hline SD & 0.093 & 0.118 & 0.105 & 0.024 & 0.008 & 0.007 \\
\hline \multicolumn{7}{|l|}{2012} \\
\hline Mean & 0.93 & 0.679 & 0.806 & 0.96 & 0.966 & 0.972 \\
\hline $\mathrm{SD}$ & 0.093 & 0.105 & 0.125 & 0.024 & 0.024 & 0.009 \\
\hline \multicolumn{7}{|l|}{2013} \\
\hline Mean & 0.941 & 0.794 & 0.822 & 0.959 & 0.969 & 0.972 \\
\hline $\mathrm{SD}$ & 0.074 & 0.174 & 0.108 & 0.025 & 0.015 & 0.01 \\
\hline \multicolumn{7}{|l|}{2014} \\
\hline Mean & 0.939 & 0.773 & 0.83 & 0.957 & 0.951 & 0.971 \\
\hline SD & 0.076 & 0.152 & 0.118 & 0.028 & 0.05 & 0.009 \\
\hline \multicolumn{7}{|c|}{$2007-2014$} \\
\hline Mean & 0.938 & 0.738 & 0.872 & 0.963 & 0.966 & 0.975 \\
\hline SD & 0.086 & 0.153 & 0.113 & 0.024 & 0.031 & 0.01 \\
\hline
\end{tabular}

With an average efficiency score of 97.5 percent, FBs are the most efficient banks from 2007 to 2014. The most inefficient banks are SOCBs with mean efficiency score equals to 73.8 percent. The second most inefficient banks are JSCBs, then CCBs, and RCBs. Hence to move to the production frontier, holding the inputs fixed, SOCBs and JSCBs should raise good loans and securities while simultaneously reducing NPLs by about 26 percent and 13 percent, respectively. There exists 
significant inefficiency in China's large banks. My findings are consistent with Berger et al. (2009) who also find that SOCBs are the least cost-efficient and FBs are the most cost-efficient over 1994-2003.

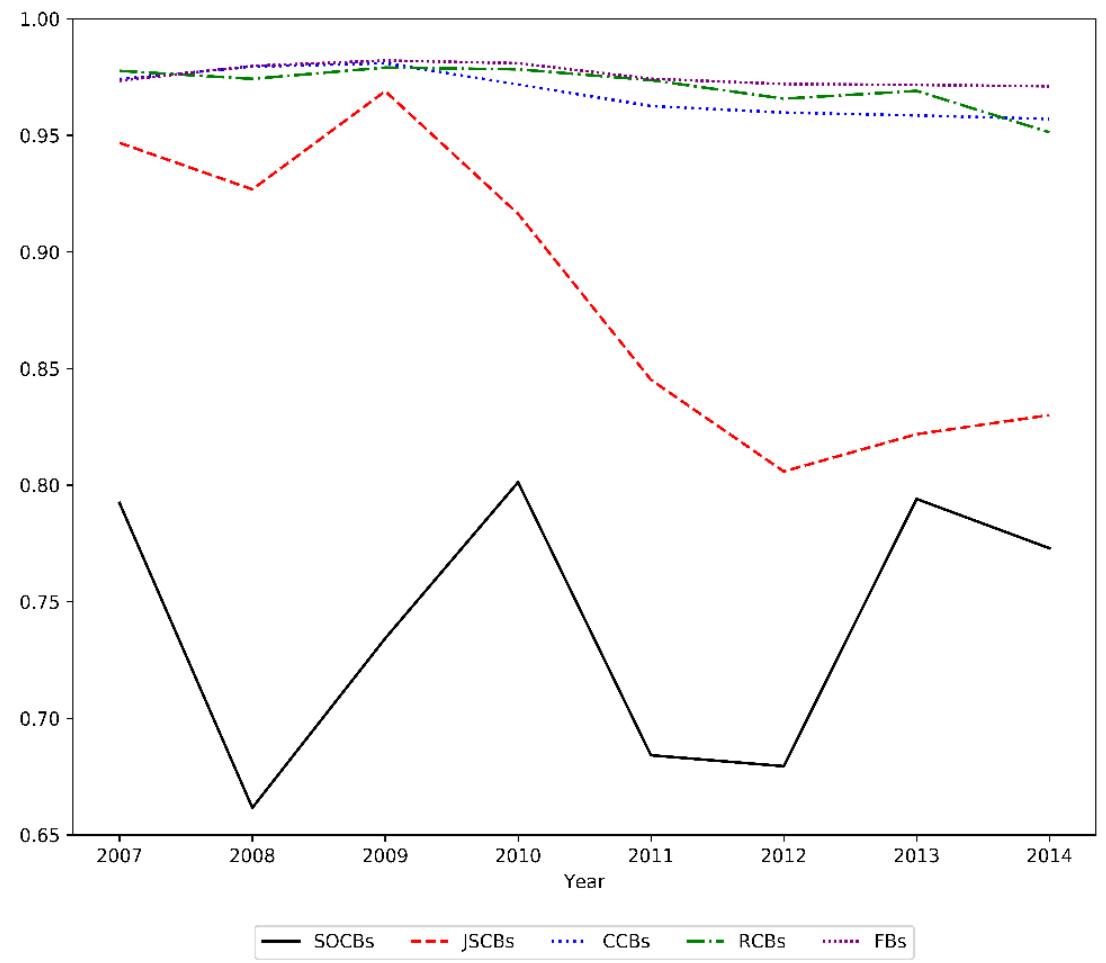

Figure 3: Technical Efficiency Scores

Figure 3 shows the trend of technical efficiency scores for each bank type from 2007 to 2014. As shown in Figure 3, the technical efficiency of both SOCBs and JSCBs has declined over 2007-2008. The decline of technical efficiency can be due to the quick rise of the default ratio in Chinese commercial banks at the start of the GFC, as shown in Figure 1. The increase in the default ratio of the lending loans at the start of the GFC negatively affects Chinese commercial banks and led to a decline in their efficiency. Moreover, Mamatzakis et al. (2016) find evidence of a reverse causal relationship between efficiency and bankrupt loans. My finding of the adverse effect of the GFC on Chinese commercial banks' efficiency, is consistent with the results in Sufian and Shah Habibullah (2010) for Thailand banks, Vu and Turnell (2011) for Australian banks, Matousek et al. (2015) for the banks in the majority of European countries, Wilson and Zhao (2019) for Chinese banks, and both Tarchouna et al. (2019) and Hasannasab et al. (2019) for U.S. commercial banks. 
However, the efficiency of SOCBs has risen over 2008-2010. The efficiency of JSCBs increased over 2008-2009. It could be explained by the decline of the default ratio over these two periods, as shown in Figure 1. The stimulus over 2008-2010 significantly increased the total loans for SOCBs and JSCBs and hence reduced the default ratio, and consequently increased their efficiency. However, the sudden expansion of the loans caused by the stimulus has caused a severe reversal effect in the years later. For JSCBs, Figure 1 shows that the default ratio has increased since 2009, and Figure 3 shows that the efficiency has decreased for 2009-2012, after which, it increases a little bit. For SOCBs, Figure 1 shows that the default ratio increases over 2010-2011, decreases a little bit over 2011-2013, and then suddenly increases a lot over 2013-2014. The efficiency for SOCBs declines from 2010 to 2011, stays almost the same from 2011 to 2012, later increases from 2012 to 2013, and declines again from 2013 to 2014. The stimulus over 2008-2010 gives the SOCBs and JSCBs a lot of pressure to quickly lend money to SOEs in a significant amount to the borrowers without thoroughly evaluating the lending quality. This action initially has a positive effect on banks' default ratio and efficiency. However, the negative impact has come out several years after the stimulus, shown by the higher default ratio and lower technical efficiency. As far as small banks like CCBs, RCBs, and FBs, are concerned, Figure 3 shows that there is no significant change in efficiency over the sample period. Thus, I conclude that the GFC and the stimulus mainly affected the large banks, like SOCBs and JSCBs.

Table 4 summarizes the mean values of prices for good (net) loans and the estimated shadow prices for NPLs by each year and by each bank type. I also report the average values of outputs prices for each bank type over the sample period at the bottom of the table. I find that the average shadow price of NPLs for all banks is 0.369 from 2007 to 2014 . The shadow price of NPLs represents the cost of reducing NPLs by one unit. Hence, it indicates that from 2007 to 2014, reducing NPLs by 1 RMB will averagely decrease the Chinese banks' revenue by 0.369 RMB due to the simultaneous decrease of good loans and securities. 
Table 4: Mean Values of Prices of Good Loans and Shadow Prices of NPLs by Year and by Bank Type

\begin{tabular}{|c|c|c|c|c|c|c|}
\hline Output Prices $^{1}$ & All & $\mathrm{SOCBs}$ & JSCBs & $\mathrm{CCBs}$ & $\mathrm{RCBs}$ & FBs \\
\hline \multicolumn{7}{|l|}{2007} \\
\hline$p_{1}$ & 0.06 & 0.06 & 0.061 & 0.066 & 0.063 & 0.04 \\
\hline $\begin{array}{l}p_{b} \\
2008\end{array}$ & 0.13 & 0.092 & 0.247 & 0.258 & 0.246 & 0.169 \\
\hline$p_{1}$ & 0.067 & 0.068 & 0.066 & 0.061 & 0.079 & 0.064 \\
\hline $\begin{array}{l}p_{b} \\
2009\end{array}$ & 0.116 & 0.064 & 0.263 & 0.28 & 0.301 & 0.263 \\
\hline$p_{1}$ & 0.047 & 0.047 & 0.048 & 0.06 & 0.062 & 0.041 \\
\hline $\begin{array}{l}p_{b} \\
2010\end{array}$ & 0.172 & 0.157 & 0.217 & 0.243 & 0.24 & 0.173 \\
\hline$p_{1}$ & 0.048 & 0.047 & 0.05 & 0.055 & 0.054 & 0.036 \\
\hline $\begin{array}{l}p_{b} \\
2011\end{array}$ & 0.249 & 0.25 & 0.251 & 0.22 & 0.21 & 0.151 \\
\hline$p_{1}$ & 0.057 & 0.054 & 0.061 & 0.066 & 0.064 & 0.052 \\
\hline $\begin{array}{l}p_{b} \\
2012\end{array}$ & 0.331 & 0.342 & 0.329 & 0.269 & 0.235 & 0.222 \\
\hline$p_{1}$ & 0.062 & 0.06 & 0.065 & 0.07 & 0.069 & 0.056 \\
\hline $\begin{array}{l}p_{b} \\
2013\end{array}$ & 0.492 & 0.617 & 0.338 & 0.284 & 0.284 & 0.216 \\
\hline$p_{1}$ & 0.059 & 0.056 & 0.062 & 0.069 & 0.066 & 0.054 \\
\hline $\begin{array}{l}p_{b} \\
2014\end{array}$ & 0.532 & 0.747 & 0.292 & 0.285 & 0.271 & 0.23 \\
\hline$p_{1}$ & 0.06 & 0.057 & 0.063 & 0.068 & 0.07 & 0.053 \\
\hline $\begin{array}{l}p_{b} \\
2007-2014\end{array}$ & 0.507 & 0.822 & 0.192 & 0.261 & 0.28 & 0.221 \\
\hline$p_{1}$ & 0.057 & 0.056 & 0.06 & 0.067 & 0.067 & 0.051 \\
\hline$p_{b}$ & 0.369 & 0.438 & 0.26 & 0.269 & 0.268 & 0.219 \\
\hline
\end{tabular}

${ }^{1}$ For each period, mean values of $p_{1}$ is weighted by performing loans $\left(y_{1}\right)$ and mean values of $p_{b}$ is weighted by non-performing loans $(b)$. 
Moreover, the diminishment of $1 \mathrm{RMB}$ of NPLs, on average, reduces the revenue of SOCBs by 0.438 , JSCBs by 0.260 , CCBs by 0.269 , RCBs by 0.268 and FBs by $0.219 \mathrm{RMB}$. The SOCBs face larger shadow price values than all the other types of banks. The higher shadow price for SOCBs indicates that the cost of reducing NPLs for SOCBs is much more "expensive" compared to all the other banks. My finding is consistent with Tarchouna et al. (2019) who find that large banks in U.S. also face higher shadow prices of NPLs than small and medium-sized banks. Moreover, Table 4 shows that the average shadow price of NPLs is significantly higher than the average price of good loans for each year and each bank type. The large difference between the shadow price of NPLs and good loans indicates asymmetric effects of generating good loans and bad loans on banks' revenue. It incurs all types of Chinese banks a significantly higher revenue loss to lessen NPLs compared to the gain in revenue generated by the same amount of good loans.

Figure 4 shows the trend of the shadow prices of NPLs for each bank type over the sample period. The estimated shadow price of NPLs for SOCBs declines from 0.092 in 2007 to 0.064 in 2008, after which it continuously increases to 0.822 in 2014. Even the estimated shadow prices for JSCBs, CCBs, RCBs, and FBs, do not vary a lot from 2007 to 2014, generally speaking, they increase from 2007 to 2008, decrease from 2008 to 2009/2010, then increase to 2012/2013, after which, they decline to 2014. The GFC's negative effect can explain the sudden rise in shadow prices for JSCBs, CCBs, RCBs, and FBs. This result is consistent with the findings of Tarchouna et al. (2019) for U.S. commercial banks and George Assaf et al. (2013) for Turkish banks. 


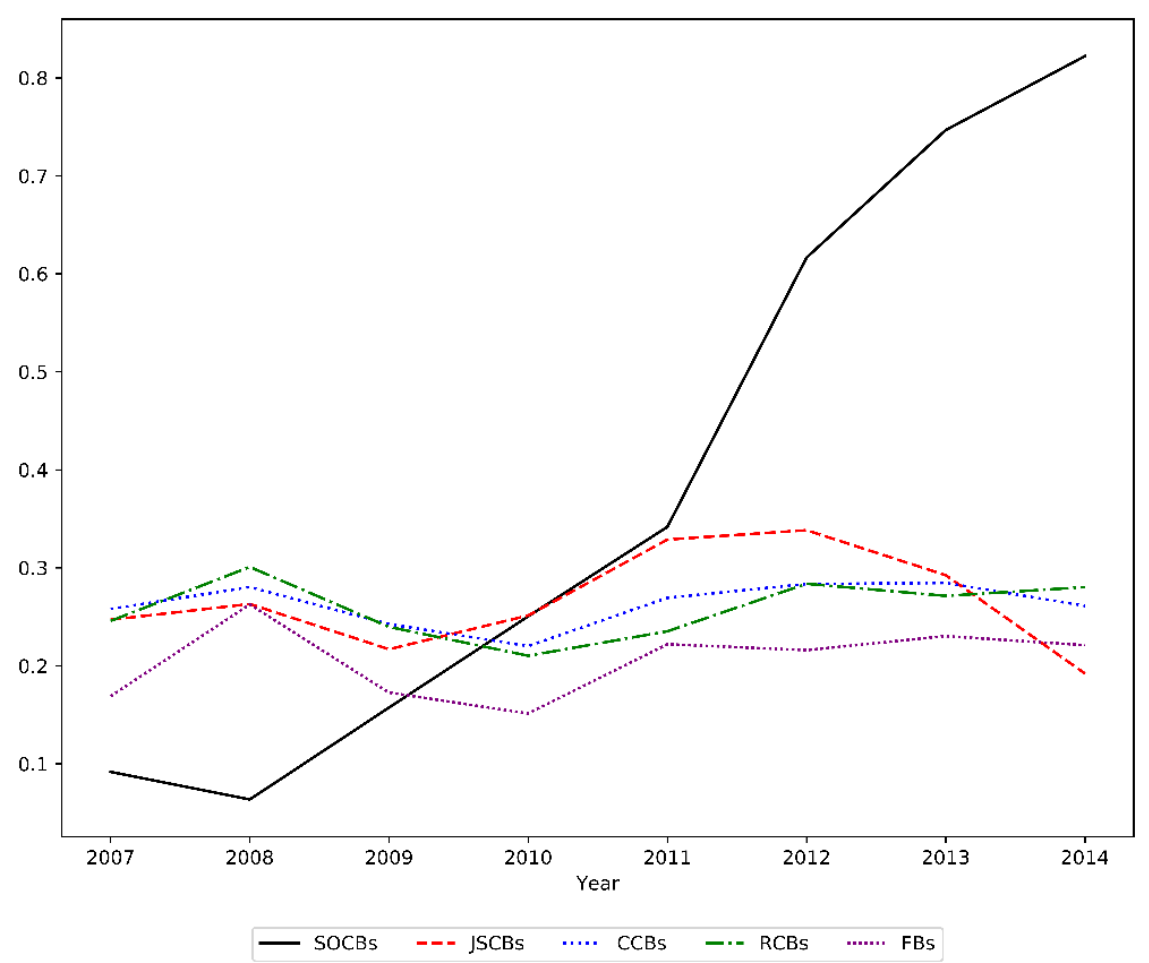

Figure 4: Price of Non-performing Loans Derived from $\boldsymbol{p}_{\mathbf{1}}$

Note: For each year and each bank type, $p_{b}$ is weighted by Non-performing Loans (b)

Moreover, starting in 2011, the shadow price of NPLs for SOCBs is higher than all the other banks. It can be explained as follows: from 2007 to 2008, compared to all the other banks, SOCBs suffer less from the GFC as they are considered to have a higher liquidity level, and hence the shadow price of NPLs for SOCBs even decreases from 2007 to 2008. However, due to the stimulus, SOCBs are forced to lend more to unqualified borrowers without fully evaluating the lending risks. Thus the lending increases their default ratio and the shadow price of NPLs and costs SOCBs more to deal with NPLs than all the other banks since 2011, one year after the stimulus. Notice that the stimulus also costs more for the other banks to deal with NPLs, as shown by the continuous increase in shadow prices of NPLs for JSCBs from 2009 to 2012, for CCBs from 2010 to 2013, for RCBs from 2010 to 2012 and FBs from 2010 to 2011. Therefore the stimulus has imposed high costs for Chinese banks to reduce NPLs. However, the decrease in shadow prices of NPLs for JSCBs, CCBs, RCBs, and FBs from 2013 to 2014, indicates that Chinese banks, except SOCBs, may have recovered from the GFC and the stimulus. 


\section{Summary and Conclusions}

The recent crisis and the stimulus have significantly disrupted the Chinese banking sector, especially causing the default ratio to increase at the start of the GFC and after the stimulus. However, no studies have evaluated the cost of reducing NPLs, the undesirable outputs arising from bank lending services, for Chinese commercial banks.

To the best of my knowledge, this study is the first to estimate the shadow price of NPLs in the Chinese banking sector. Moreover, by modeling NPLs as a jointly produced undesirable output, I estimate the banks' technical efficiency during the GFC and the stimulus. I employ a quadratic form for the directional output distance function and calculate it using Aigner and Chu (1968) method for a sample of 534 bank observations over the period 2007-2014 covering both the GFC and the stimulus period. The shadow prices of NPLs are then derived from the observable market price of good loans and the physical trade-off between good loans and NPLs. By rigorously comparing the technical efficiency and the shadow prices of NPLs across the sample years and different bank types, I find that the SOCBs are the least efficient and foreign banks are the most efficient banks from 2007 to 2014. I also find that the GFC harms banks' efficiency. The stimulus initially has a positive effect on SOCBs and JSCBs, but later shows a negative impact with a higher default ratio and lower efficiency. Moreover, the results show that starting in 2011, the shadow prices of NPLs for SOCBs are much higher than all other bank types. The shadow prices of JSCBs, CCBs, RCBs, and FBs rise sharply from 2007 to 2008, and this is due to the negative effect of the GFC. Finally, I find that the stimulus has dramatically increased the opportunity cost of lessening NPLs for SOCBs.

Hence although the stimulus helps the Chinese economy quickly recover from the crisis, it has imposed a high cost on large Chinese banks like SOCBs and JSCBs. Therefore, policymakers and bank managers should be cautious and take the cost of lessening NPLs into account whenever making investment plans in the future.

\section{ACKNOWLEDGEMENTS}

I thank the Cyber Infrastructure Technology Integration group at Clemson University for operating the Palmetto cluster used for the computations. At the initial stage of the project, I received helpful suggestions from Dr. Paul Wilson. In addition, I thank Dr. Benjamin Posmanick for his comments and careful edits. All remaining errors are my own. 


\section{References}

[1] Aigner, D. J. and S. F. Chu (1968), On Estimating the Industry Production Function, The American Economic Review 58, 826-839.

[2] Berger, A. N., I. Hasan, and M. Zhou (2009), Bank ownership and efficiency in China: What will happen in the world's largest nation?, Journal of Banking \& Finance 33, 113-130.

[3] Boyd, G. A., G. Tolley, and J. Pang (2002), Plant Level Productivity, Efficiency, and Environmental Performance of the Container Glass Industry, Environmental and Resource Economics 23, 29-43.

[4] Fukuyama, H. and W. L. Weber (2008a), Estimating Inefficiency, Technological Change and Shadow Prices of Problem Loans for Regional Banks and Shinkin Banks in Japan, The Open Management Journal 1, 1-11. (2008b), Japanese banking inefficiency and shadow pricing, Mathematical and Computer Modelling 48, 1854-1867.

[5] Färe, R., S. Grosskopf, C. A. K. Lovell, and S. Yaisawarng (1993), Derivation of Shadow Prices for Undesirable Outputs: A Distance Function Approach, The Review of Economics and Statistics 75, 374-380.

[6] Färe, R., S. Grosskopf, D.-W. Noh, and W. Weber (2005), Characteristics of a polluting technology: theory and practice, Journal of Econometrics 126, 469492.

[7] George Assaf, A., R. Matousek, and E. G. Tsionas (2013), Turkish bank efficiency: Bayesian estimation with undesirable outputs, Journal of Banking \& Finance 37, 506-517.

[8] Guarda, P., A. Rouabah, and M. Vardanyan (2013), Identifying bank outputs and inputs with a directional technology distance function, Journal of Productivity Analysis 40, 185-195.

[9] Hasannasab, M., D. Margaritis, and C. Staikouras (2019), The financial crisis and the shadow price of bank capital, Annals of Operations Research 282, 131154.

[10] Lee, C.-Y. and P. Zhou (2015), Directional shadow price estimation of CO2, SO2 and NOx in the United States coal power industry 1990-2010, Energy Economics 51, 493-502.

[11] Mamatzakis, E., R. Matousek, and A. N. Vu (2016), What is the impact of bankrupt and restructured loans on Japanese bank efficiency?, Journal of Banking \& Finance 72, S187-S202.

[12] Matousek, R., A. Rughoo, N. Sarantis, and A. George Assaf (2015), Bank performance and convergence during the financial crisis: Evidence from the 'old' European Union and Eurozone, Journal of Banking \& Finance 52, 208216.

[13] Partovi, E. and R. Matousek (2019), Bank efficiency and non-performing loans: Evidence from Turkey, Research in International Business and Finance 48, 287-309. 
[14] Sealey, C. W. and J. T. Lindley (1977), Inputs, Outputs, and a Theory of Production and Cost at Depository Financial Institutions, The Journal of Finance 32, 1251-1266.

[15] Sufian, F. and M. Shah Habibullah (2010), Developments in the efficiency of the Thailand banking sector: a DEA approach, International Journal of Development Issues 9, 226-245.

[16] Tarchouna, A., B. Jarraya, and A. Bouri (2019), Shadow prices of nonperforming loans and the global financial crisis: Empirical evidence from US commercial banks, The Journal of Risk Finance 20, 411-434.

[17] Vu, H. and S. Turnell (2011), Cost and Profit Efficiencies of Australian Banks and the Impact of the Global Financial Crisis, Economic Record 87, 525-536.

[18] Wilson, P. and S. Zhao (2019), Performance of chinese banks over 2007-2014. Available at https://www.semanticscholar.org/paper/Performance-of-ChineseBanks-over-2007\%E2\%80\%932014-WilsonZhao/bf73193f948dc3b362648f6ee6e7831917ef7cca.

[19] Zhao, S. (2020), The shadow prices of CO2, SO2 and NOx for U.S. coal power industry 2010-2017: A convex quantile regression method. Available at https://papers.ssrn.com/sol3/papers.cfm?abstract id=3692709.

[20] Zhou, P., X. Zhou, and L. W. Fan (2014), On estimating shadow prices of undesirable outputs with efficiency models: A literature review, Applied Energy 130, 799-806.

[21] Zhu, N., B. Wang, and Y. Wu (2015), Productivity, efficiency, and nonperforming loans in the Chinese banking industry, The Social Science Journal 52, 468-480. 